\title{
Percepção de Acadêmicos de Medicina e de Outras Áreas da Saúde e Humanas (Ligadas à Saúde) sobre as Relações entre Espiritualidade, Religiosidade e Saúde The Perception of Medical Students as well as Students from Other Health-Related Areas Regarding the Relations between Spirituality, Religiosity and Health
}

\author{
Tassiani Turra Ferreira ${ }^{I}$ \\ Maria de Fátima Borges ${ }^{I}$ \\ Guilherme Cia Zanetti ${ }^{I}$ \\ Gustavo Luis Lemos ${ }^{I}$ \\ Eduardo Souza Gotti ${ }^{I}$ \\ Janaíne Machado Tomér \\ Adriana Paula da Silva ${ }^{I}$ \\ Elisabete Aparecida Mantovani Rodrigues de RezendeI
}

PALAVRAS-CHAVE

- Religião.

- Espiritualidade.

- Educação em Saúde.

- Currículo.

- Medicina.

- Psicologia.

- Percepção.

\begin{abstract}
Introdução: Alguns autores encontraram relação estreita e positiva da religiosidade e espiritualidade com comportamentos saudáveis, resultando em saúde adequada. Além disso, dados da literatura sugerem que, de modo geral, as pessoas se apoiam em suas crenças para enfrentar momentos de dificuldades pessoais e coletivas. Os profissionais cujas práticas estão ligadas ao cuidado em saúde necessitam se capacitar para atender e respeitar as manifestações e necessidades dos pacientes no que se refere a religiosidade e espiritualidade. Objetivos: Investigar o que pensam os acadêmicos ingressantes no curso de Medicina e de outras áreas da saúde e humanas acerca do tema; identificar o papel e a importância da religiosidade e espiritualidade em suas vidas e futuras práticas profissionais. Metodologia: Trata-se de estudo quantitativo-qualitativo, descritivo, transversal, de amostra intencional. Entre fevereiro e abril de 2014, foi aplicado aos acadêmicos do primeiro período de Medicina, Biomedicina, Enfermagem, Fisioterapia, Terapia Ocupacional, Educação Física, Nutrição, Psicologia e Serviço Social um questionário que avaliou variáveis sociodemográficas e conceitos que envolvem religiosidade e espiritualidade e saúde. A análise dos dados empregou Qui-Quadrado clássico, feita pelo SPSS versão 2.0, e P < 0,05 foi considerado significante. Resultados: Foram selecionados 270 alunos, de 18 a 43 anos; entretanto, 183 preencheram o questionário, sendo a maioria do sexo feminino, de família convencional, cristãl católica, que herdou a religião dos pais; 78,6\% (144/183) referiram afiliação religiosa, 43,5\% (87/183) a exercem de forma organizacional. A maioria dos indivíduos considerou que a religiosidade e espiritualidade confere sentido a suas vidas, fortalece em momentos difíceis, traz benefícios à saúde, e considera importante a abordagem de temas relacionados em sua formação acadêmica, enquanto 31,4\% (57/183) referiram que houve influência da religiosidade e espiritualidade na escolha profissional. Conclusão: Os alunos das áreas estudadas que ingressaram na Universidade Federal do Triângulo Mineiro manifestaram características positivas relacionadas ao tema religiosidade e espiritualidade, e têm expectativa de uma abordagem mais integral e espiritual do homem na grade curricular.
\end{abstract}




\section{KEY-WORDS}

- Religion

- Spirituality.

- Health, Education.

- Curriculum in Health.

- Medicine.

- Psychology.

- Perception.

Recebido em 24/10/2016

Aceito em 18/10/2017

\section{ABSTRACT}

Introduction: Some authors have found close and positive relationship between religiosity and spirituality and healthy behaviors that result in good health. Furthermore, data drawn from the literature suggest that, in general, people rely on their beliefs to face moments of personal and collective difficulties. Professionals whose practices are linked to health care, need to be trained to meet and observe the needs of patients, in terms of religiosity and spirituality. Objective: To investigate what medical students as well as students in the health area think about this topic, in addition to identifying the role and importance they attribute to religiosity and spirituality in their lives and future professional practices. Methodology: This was a quantitative and qualitative, descriptive, cross intentional sample study. We applied a questionnaire to first-year students of medicine, biomedicine, nursing, physiotherapy, occupational therapy, physical education, nutrition, psychology and social service, which assessed socio-demographic variables and concepts involving religiosity and spirituality and health. For the data analysis, we used the Chi-Square test developed in SPSS version 2.0, and P<0.05 was considered significant. Results: We selected 270 students, aged between 18 and 43, however, only 183 completed the questionnaire. The majority of the respondents were female, who come from conventional Catholic and Christian families, and inherited their religion from their parents; $78.6 \%$ (144/183) report religious affiliation, 43.5\% (87/183) practice it in a disciplined way. Most the individuals considered that $R / S$ gives meaning to their lives, strengthens them in times of trouble and brings benefits to their health. They also consider religiosity and spirituality and issues related issues as very important to their academic background, whereas 31.4\% (57/183) quoted that religiosity and spirituality have influenced their professional choice. Conclusion: Those who have become students at the Universidade Federal do Triângulo Mineiro have a positive attitude towards religiosity and spirituality and expect a more comprhensive and spiritual approach towards their curriculum.

\section{INTRODUÇÃO}

As conexões entre saúde e espiritualidade e/ou religiosidade/espiritualidade $(\mathrm{R} / \mathrm{E})$ têm raízes profundas e complexas na história e evolução da humanidade ${ }^{1}$. O cuidado aos doentes por comunidades religiosas foi uma das principais heranças do cristianismo, tendo exercido indubitável influência na fundação de casas de apoio e assistência que evoluíram para a organização de hospitais, estando os preceitos cristãos presentes na memória coletiva que norteou a formação de profissionais de saúde, sobretudo na área de enfermagem². Após uma separação de quase 500 anos entre ciência e religiosidade, necessária ao desenvolvimento da ciência sem a obstrução à liberdade do pensamento na forma de fé religiosa autoritária, elas se interconectam cada vez mais por meio da pesquisa científica, que vem demonstrando a importância e influência da fé no enfrentamento de várias situações de vulnerabilidade física e psíquica do ser humano, apontando a necessidade de reconstruir as inter-relações entre ciência e R/E ${ }^{3}$.

Os termos "espiritualidade" e "religiosidade" têm sido empregados como sinônimos em pesquisa, mas, segundo
Koenig et al. ${ }^{3}$, religiosidade se refere ao envolvimento do indivíduo com um sistema organizado de crenças, práticas, rituais e símbolos, utilizados para facilitar o acesso ao transcendente, engajando-o em afiliação religiosa e comunidade definidas. Espiritualidade, por sua vez, consiste na busca individual por significado e sentido da vida e de suas relações com o transcendente ou sagrado, podendo incluir ou não uma participação religiosa formal, sendo de mensuração mais difícil do que religiosidade. Em termos práticos e em pesquisa, utilizam-se os dois termos como sinônimos, com a finalidade de abranger as duas dimensões da ligação dos indivíduos com o transcendente ${ }^{3}$.

Recentemente, surgiu o termo "espiritualidade baseada em evidências" ${ }^{4}$, sugerindo que existe uma base científica nos moldes tradicionais entre saúde/doença e R/E. De fato, ao longo das últimas duas décadas, acumularam-se evidências de que o exercício de atividades espirituais/religiosas pode influenciar positivamente inúmeros aspectos da saúde humana, do ponto de vista físico ou mental ${ }^{4}$.

REVISTA BRASILEIRA DE EDUCAÇ̃̃̃O MÉDICA

$\left.68\right|_{42(1): 62-74 ; 2018}$ 
Alguns estudos têm enfatizado que o cuidado em saúde deve abordar os indivíduos de forma integral, abrangendo os aspectos biológicos, psicológicos e sociais, mas acrescentando a questão espiritual à experiência humana. Este conceito ultrapassa a concepção mecanicista do homem, responsável pela assistência fragmentada, e incorpora dimensões subjetivas, mas importantes, dos indivíduos. Na busca da visão integral, a abordagem da R/E tem sido um meio eficaz de aprimorar o cuidado nos estados de saúde e doença ${ }^{4-6}$.

O presente estudo teve por objetivo analisar a percepção de acadêmicos de Medicina e das áreas de saúde e humanas (relacionadas à saúde) recém-matriculados no primeiro período, na Universidade Federal do Triângulo Mineiro, acerca das relações entre R/E e saúde, o conhecimento e a importância atribuídos ao tema, assim como identificar as expectativas dos indivíduos quanto à inserção da espiritualidade como parte do atendimento integral em suas futuras práticas profissionais.

\section{SUJEITOS E MÉTODOS}

Trata-se de estudo quantitativo-qualitativo, desenhado para investigar os aspectos objetivos e subjetivos apresentados pelos sujeitos avaliados pela pesquisa, de caráter descritivo e observacional. Foi aprovado pelo CEP da UFTM, protocolo $\mathrm{n}^{\circ}$ 2.550. Foi aplicado um questionário semiestruturado e dirigido aos acadêmicos de primeiro período, sendo, assim, um estudo transversal de amostra intencional.

Foram convidados a participar os estudantes universitários recém-matriculados no primeiro período dos cursos de Medicina, Biomedicina, Educação Física, Enfermagem, Fisioterapia, Nutrição, Terapia Ocupacional, Psicologia e Serviço Social. Foram incluídos os maiores de 18 anos e que aceitaram responder ao questionário e assinar o Termo de Consentimento Livre e Esclarecido (TCLE). Os alunos do primeiro ano foram eleitos porque ainda não haviam tido contato com o programa dos cursos e, portanto, ainda não haviam sido influenciados pela experiência universitária.

$\mathrm{O}$ instrumento aplicado foi um questionário padrão, impresso em papel, semiestruturado, elaborado pelos autores e constituído por 27 questões, algumas com respostas sim ou não ou de múltipla escolha, mas com algumas questões de margem aberta que davam opções ao discente para elaborar suas respostas. Para o presente estudo, foram utilizadas as seguintes questões:

- Dados sociodemográficos dos discentes e família (questões de 1 a 13): curso em que estava matriculado, procedência, idade, gênero, autorreferência à cor da pele, formação educacional prévia, estado civil, condição financeira própria e da família, expressa em número de salários mínimos, caracterís- ticas da constituição da família em habitual ou convencional (pai, mãe, irmãos) e não convencional, bem como nível escolar dos pais ou responsáveis;

- Questões de 14 a 21: inspiradas em Koenig et al. ${ }^{7}$, para avaliar religiosidade intrínseca (RI) e extrínseca (RE), mas sem utilizar escores específicos pelo fato de o questionário Durel ter sido idealizado para avaliar doentes e não discentes;

- Questão 22: para avaliar a percepção dos discentes quanto às diferenças entre os conceitos de espiritualidade e religiosidade na visão intuitiva deles, sendo uma questão semiaberta;

- Questões de 23 a 27: para avaliar a expectativa dos alunos quanto à presença de temas que envolvem saúde e espiritualidade no seu currículo e o que eles pensam acerca da relação entre saúde e espiritualidade.

Os dados foram coletados nas salas de aula do Centro Educacional da UFTM entre fevereiro e abril de 2014 com a permissão prévia do professor da disciplina que estivesse sendo ministrada no momento. O tempo previsto para o preenchimento do questionário foi de 20 minutos.

As variáveis contínuas foram submetidas ao teste de distribuição de normalidade de Kolmogorov-Smirnov, e a homogeneidade das variâncias verificada pelo teste de Levene. Os resultados quantitativos foram submetidos à estatística descritiva (média, desvio padrão e frequências), adaptada às condições específicas dos mesmos conforme a distribuição de normalidade. As variáveis categóricas foram submetidas ao teste do Qui-Quadrado $\left(\mathrm{X}^{2}\right)$ clássico com análise de resíduo, e foram considerados significativos os resultados que apresentaram nível de significância $(P)$ menor que 0,05. A análise de dados utilizou o software Statistical Package for the Social Sciences (SPSS) versão 20.

\section{RESULTADOS}

O número de alunos de primeiro período dos cursos selecionados para análise era de 270. Cento e oitenta e três alunos aceitaram fazer parte do estudo, sendo este o número de questionários distribuídos, preenchidos e válidos para o estudo.

A Tabela 1 apresenta a distribuição dos indivíduos analisados, por curso e gênero. Na amostra houve predomínio do sexo feminino na maioria dos cursos, sendo que no Serviço Social, Terapia Ocupacional e Enfermagem esta diferença foi estatisticamente significante $(\mathrm{p}<0,05)$. Ao contrário, nos cursos de Medicina e Educação Física houve predomínio do sexo masculino $(\mathrm{p}<0,05)$. A idade dos entrevistados variou de 18 a 43 anos (mediana: 19), sendo 171 solteiros, 6 casados, $3 \mathrm{em}$ união estável, 2 divorciados e 1 indivíduo não respondeu. A cor da pele foi autorreferida, e a amostra era, em sua maioria, da cor branca ( $n=127,69,4 \%$ ), 5,5\% da cor preta, $20,2 \%$ de pardos, 2,6\% da cor amarela, e 2,2\% não responderam.

$69 \mid \begin{aligned} & \text { REVISTA BRASILEIRA DE EDUCAÇÃO MÉDICA } \\ & \text { 42(1):62 }\end{aligned}$

$\left.69\right|_{42(1): 62-74 ; 2018}$ 


\begin{tabular}{|c|c|c|c|}
\hline \multicolumn{4}{|c|}{$\begin{array}{c}\text { TABELA } 1 \\
\text { Distribuição dos acadêmicos entrevistados, } \\
\text { segundo curso e gênero }\end{array}$} \\
\hline Curso & n (\%) & $\begin{array}{c}\text { Masculino } \\
\text { n (\%) }\end{array}$ & $\begin{array}{c}\text { Feminino } \\
\mathrm{n}(\%)\end{array}$ \\
\hline Psicologia & $25(13,7)$ & $6(24,0)$ & $19(76,0)$ \\
\hline Medicina & $28(15,3)$ & $20(71,4)^{*}$ & $8(28,5)^{*}$ \\
\hline Biomedicina & $18(9,8)$ & $5(27,7)$ & $13(72,2)$ \\
\hline Fisioterapia & $24(13,1)$ & $6(25,0)$ & $18(75,0)$ \\
\hline Terapia Ocupacional & $9(4,9)$ & $0(0,0)$ & $9(100,0)^{*}$ \\
\hline Enfermagem & $11(6,1)$ & $0(0,0)$ & $11(100,0)^{*}$ \\
\hline Educação Física & $26(14,2)$ & $17(65,3)^{*}$ & $9(34,6)^{*}$ \\
\hline Nutrição & $24(13,1)$ & $5(20,8)$ & $19(79,1)$ \\
\hline Serviço Social & $18(9,8)$ & $1(5,5)^{*}$ & $17(94,4)^{*}$ \\
\hline Total & $183(100,0)$ & 60 & 123 \\
\hline
\end{tabular}

* $p<0,05$; teste do Qui-Quadrado, com análise de resíduo. Fonte: a autora.

Os indivíduos provenientes de instituição privada constituíram 44,8\% $(n=82)$ da amostra, enquanto $37,2 \%(n=68)$ eram provenientes de ensino público, e uma minoria - $16,9 \%$ ( $n=31)$ - estudou nos dois sistemas educacionais. A esta questão não responderam duas pessoas (1,1\%). Quanto à escolaridade dos pais e/ou dos responsáveis, se dividiu em nível fundamental $(n=45) 24,6 \%$, médio $(n=60) 32,8 \%$, superior $(n$ = 76) $41,5 \%$, e duas pessoas (1,1\%) não responderam.

A maioria dos indivíduos, 93\% $(\mathrm{n}=171)$, referiu estrutura familiar convencional, e 91,8\% ( $\mathrm{n}=168)$ ainda sem renda pró- pria; $61,2 \%$ dos indivíduos $(\mathrm{n}=112)$ referiram renda familiar entre três e seis salários mínimos. Todos eram brasileiros, e a maioria - 90,7\% ( $n=166)$ - procedente dos estados de São Paulo e Minas Gerais.

Apenas três indivíduos declararam ser portadores de necessidades especiais, sendo um deficiente físico e duas pessoas não especificaram.

A distribuição dos indivíduos segundo a religião referida está representada na Tabela 2, e a distribuição dos indivíduos quanto à afiliação religiosa por curso frequentado se encontra na Tabela 3.

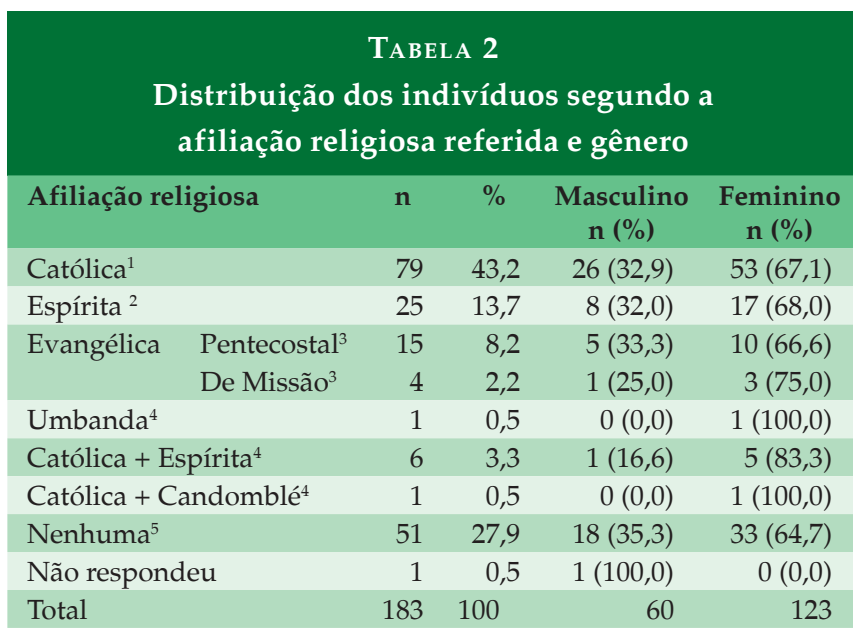

1,2,3,4,5 $p>0,05$; teste do Qui-Quadrado, com análise de resíduo.

Fonte: a autora.

\begin{tabular}{|c|c|c|c|c|c|c|c|c|c|}
\hline \multicolumn{10}{|c|}{$\begin{array}{c}\text { TABELA } 3 \\
\text { Distribuição da afiliação religiosa dos acadêmicos segundo o curso frequentado }\end{array}$} \\
\hline $\begin{array}{l}\text { Curso } \\
\text { (n total) }\end{array}$ & $\begin{array}{c}\text { Sem resposta } \\
\text { n }(\%)\end{array}$ & $\begin{array}{c}\text { Católica } \\
\text { n (\%) }\end{array}$ & $\begin{array}{l}\text { Espírita } \\
\text { n (\%) }\end{array}$ & $\begin{array}{c}\text { Evangélica } \\
\text { n (\%) }\end{array}$ & $\begin{array}{c}\text { Protestante } \\
\text { n (\%) }\end{array}$ & $\begin{array}{c}\text { Umbanda } \\
\text { n (\%) }\end{array}$ & $\begin{array}{c}\text { Católica/Espírita } \\
\text { n ( } \%)\end{array}$ & $\begin{array}{c}\text { Nenhuma } \\
\text { n (\%) }\end{array}$ & $\begin{array}{l}\text { Católica/ } \\
\text { Candomblé } \\
\text { n (\%) }\end{array}$ \\
\hline $\begin{array}{l}\text { Psicologia } \\
(n=25)\end{array}$ & - & $10(40,0)$ & $1(4,0)$ & - & - & - & - & $14(56,0)$ & - \\
\hline $\begin{array}{l}\text { Medicina } \\
(\mathrm{n}=28)\end{array}$ & $1(3,6)$ & $11(39,3)$ & $3(10,7)$ & $2(7,1)$ & $3(10,7)$ & - & - & $8(28,6)$ & - \\
\hline $\begin{array}{l}\text { Biomedicina } \\
(\mathrm{n}=18)\end{array}$ & - & $6(33,3)$ & $3(16,7)$ & $1(5,6)$ & - & $1(5,6)$ & - & $7(38,9)$ & - \\
\hline $\begin{array}{l}\text { T. Ocupacional } \\
(n=9)\end{array}$ & - & $2(22,2)$ & $2(22,2)$ & $2(22,2)$ & - & - & $1(11,1)$ & $2(22,2)$ & - \\
\hline $\begin{array}{l}\text { Enfermagem } \\
(\mathrm{n}=11)\end{array}$ & - & $5(45,5)$ & - & $1(9,1)$ & - & - & $1(9,1)$ & $4(36,4)$ & - \\
\hline $\begin{array}{l}\text { Serviço Social } \\
(n=18)\end{array}$ & - & $5(27,8)$ & $4(22,2)$ & $5(27,8)$ & - & - & $1(5,6)$ & $3(16,7)$ & - \\
\hline $\begin{array}{l}\text { Fisioterapia } \\
(\mathrm{n}=24)\end{array}$ & - & $15(62,5)$ & $4(16,7)$ & $3(12,5)$ & - & - & - & $2(8,3)$ & - \\
\hline $\begin{array}{l}\text { Nutrição } \\
(\mathrm{n}=24)\end{array}$ & - & $12(50,0)$ & $3(12,5)$ & - & $1(4,2)$ & - & $1(4,2)$ & $7(29,2)$ & - \\
\hline $\begin{array}{l}\text { Educação Física } \\
(\mathrm{n}=26)\end{array}$ & - & $13(50,0)$ & $5(19,2)$ & $1(3,8)$ & - & - & $2(7,7)$ & $4(15,4)$ & $1(3,8)$ \\
\hline Total (183) & $0,5(1)$ & $79(43,2)$ & $25(13,7)$ & $15(8,2)$ & $4(2,2)$ & $1(0,5)$ & $6(3,3)$ & $51(27,9)$ & $1(0,5)$ \\
\hline
\end{tabular}

$P>0,05$ para o teste.

Fonte: a autora. 
A religião referida pelos indivíduos foi a mesma dos pais em $67,2 \%(n=123)$, e 32,2\% $(n=59)$ diferiram da religião dos pais; um indivíduo não respondeu; $78,6 \%$ das pessoas $(n=144)$ referiram engajamento a um grupo religioso, e 43,5\% ( $n=87)$ referiram exercer sua religião de forma organizacional.

A Tabela 4 apresenta a participação dos indivíduos entrevistados com relação à frequência a templos religiosos, à vivência de $\mathrm{R} / \mathrm{E}$ no grupo familiar e à participação em eventos que abordavam temas de R/E.

\begin{tabular}{|c|c|c|c|}
\hline \multicolumn{4}{|c|}{$\begin{array}{l}\text { TABELA } 4 \\
\text { Distribuição dos entrevistados com relação a frequência } \\
\text { a templos religiosos, vivência da religiosidade } \\
\text { e espiritualidade (R/E) em grupos familiares e } \\
\text { participação em eventos que abordam estes temas }\end{array}$} \\
\hline Manifesta & $\begin{array}{l}\text { Sim } \\
\text { n (\%) }\end{array}$ & $\begin{array}{l}\text { Não } \\
\text { n (\%) }\end{array}$ & $\begin{array}{c}\text { Sem resposta } \\
\text { n (\%) }\end{array}$ \\
\hline Vivência $\mathrm{f}$ & 79( & 4( & - \\
\hline Frequência a templos & $125(68,3)^{\#}$ & & \\
\hline Participação em eventos & $24(13,1)$ & $157(85,7)$ & $2(1,09)$ \\
\hline
\end{tabular}

\# Dos 125 entrevistados que responderam frequentar templos religiosos, 30\% $(n=55)$ frequentam uma vez por semana, $6 \%(n=11)$ duas vezes por semana e $32 \%(n=59)$ esporadicamente.

Fonte: a autora.

\begin{tabular}{|c|c|c|c|c|}
\hline \multicolumn{5}{|c|}{$\begin{array}{c}\text { TABELA } 5 \\
\text { Respostas dos } 183 \text { acadêmicos selecionados } \\
\text { acerca das questões que envolvem crenças acerca } \\
\text { da religiosidade e espiritualidade (R/E) }\end{array}$} \\
\hline Questões propostas & $\begin{array}{l}\text { Sim } \\
\text { n (\%) }\end{array}$ & $\begin{array}{l}\text { Não } \\
\text { n (\%) }\end{array}$ & $\begin{array}{l}\text { Sem } \\
\text { resposta } \\
\text { n (\%) }\end{array}$ & $\begin{array}{c}\text { Sem } \\
\text { opinião } \\
\text { n (\%) }\end{array}$ \\
\hline $\begin{array}{l}\text { Crença na vida após } \\
\text { a morte }\end{array}$ & $130(71,0)$ & $33(18,0)$ & 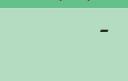 & $20(10,9)$ \\
\hline R/E dá sentido à vida & $141(77,0)$ & $42(22,9)$ & $2(1,09)$ & \\
\hline $\begin{array}{l}\mathrm{R} / \mathrm{E} \text { confere } \\
\text { resistência em } \\
\text { momentos difíceis }\end{array}$ & $163(89,1)$ & $20(10,9)$ & - & \\
\hline $\begin{array}{l}\text { Os termos R/E têm } \\
\text { o mesmo significado? }\end{array}$ & $49(26,7)$ & $76(41,5)$ & - & $58(31,6)$ \\
\hline $\begin{array}{l}\text { Importância de } \\
\text { temas de R/E no } \\
\text { currículo }\end{array}$ & $157(85,7)$ & $26(14,2)$ & - & \\
\hline $\begin{array}{l}\mathrm{R} / \mathrm{E} \text { confere } \\
\text { benefícios à saúde }\end{array}$ & $175(85,7)$ & $26(14,2)$ & - & \\
\hline $\begin{array}{l}\mathrm{R} / \mathrm{E} \text { confere } \\
\text { malefícios à saúde }\end{array}$ & $86(46,9)$ & $95(51,9)$ & $2(1,09)$ & \\
\hline $\begin{array}{l}\text { Influência na escolha } \\
\text { profissional }\end{array}$ & $57(31,4)$ & $124(67,7)$ & $2(1,09)$ & \\
\hline
\end{tabular}

Fonte: A autora.

Algumas questões que envolvem crenças espirituais estão apresentadas na Tabela 5. A maioria dos indivíduos conside- rou que a $\mathrm{R} / \mathrm{E}$ confere sentido à vida, fortalece em momentos difíceis, confere benefícios à saúde e considera importante a abordagem de temas relacionados à influência da R/E na saúde durante a formação acadêmica; 31,4\% dos indivíduos ( $n=57$ ) referiram que houve influência da $\mathrm{R} / \mathrm{E}$ na escolha profissional. Indagados acerca de possíveis malefícios à saúde, $51,91 \%(n=95)$ responderam afirmativamente, mas apenas $36,0 \%(n=66)$ justificaram a resposta.

Com relação ao significado dos termos "espiritualidade" e "religiosidade", 26,7\% $(n=49)$ responderam que são sinônimos, $41,5 \%(n=76)$ disseram que os termos são diferentes, e $31,6 \%(n=58)$ não tinham opinião formada sobre o assunto.

À questão "Você acredita que há uma vida espiritual após a morte?", $71 \%$ dos entrevistados $(n=130)$ responderam que $\operatorname{sim}, 18 \%(n=33)$ responderam que não, enquanto $10,9 \%(n=$ 20) disseram que não tinham opinião formada sobre a questão (Tabela 5).

Não houve correlação significante entre crença na vida espiritual após a morte e gênero, escolaridade do responsável, renda familiar, afiliação religiosa e o curso frequentado pelo aluno. Entretanto, 100\% dos espíritas, 73,4\% dos católicos, $53,3 \%$ dos evangélicos pentecostais e os dois indivíduos de religiões afro-brasileiras afirmaram sua crença na vida espiritual após a morte. Em relação ao curso, a maioria dos entrevistados também afirmou a mesma crença.

Às questões "Crenças espirituais dão sentido à vida?" e "Crenças espirituais lhe dão forças em momentos difíceis", a maioria dos indivíduos entrevistados respondeu "sim"; entretanto, não houve associação significante da resposta com gênero, afiliação religiosa, curso, escolaridade do responsável e renda familiar.

Dos entrevistados, $24 \%(n=44)$ referem não exercer a religiosidade, $21,9 \%(n=40)$ exercem de forma organizacional (frequentam templos regularmente), 29,5\% ( $n=54)$ exercem de forma não organizacional (não vão a templos, mas fazem leituras e preces em casa), e 24,6\% (n=45) atuam de ambas as formas. $\mathrm{O}$ grupo católico apresentou frequência significantemente maior de indivíduos que exercem $\mathrm{R} / \mathrm{E}$ de forma organizacional ( $n=26 ; 32,0 \%$ ), bem como a menor frequência de indivíduos que não exercem a $\mathrm{R} / \mathrm{E}$ de nenhuma forma $(\mathrm{n}=14$; $17,7 \%$ ). Não se observou associação entre a forma de exercer a religiosidade e o curso frequentado, a escolaridade do responsável e a renda familiar.

Em relação à importância de abordar os temas relacionados à saúde durante a formação acadêmica, 85,9\% (n = 157) dos indivíduos entrevistados responderam que é relevante incluir o tema; entretanto, não houve associação entre a resposta e gênero, afiliação religiosa, escolaridade do responsável e 
renda familiar. Em relação ao curso, os acadêmicos de Biomedicina tiveram uma frequência maior de respostas afirmativas ( $n=12 ; 66,7 \%$ ), enquanto os acadêmicos de Nutrição tiveram a menor frequência de respostas afirmativas ( $n=8 ; 33,0 \%$ ).

Quanto aos benefícios e malefícios que a R/E possa trazer às pessoas, $94,5 \%(n=173)$ dos entrevistados acreditam que traz benefícios, enquanto $47,6 \%(n=86)$ acreditam que traz malefícios; estes dados foram independentes de gênero, escolaridade, renda familiar, curso ou afiliação religiosa.

Quanto à influência da R/E na escolha profissional, 67,8\% ( $n=124$ ) dos entrevistados referiram que não houve, com exceção do curso de Serviço Social, em que 55,6\% (n = 10/18) referiram que houve influência na escolha profissional.

\section{DISCUSSÃO}

O perfil sociodemográfico dos alunos entrevistados mostrou que a maioria é jovem (mediana de idade: 19 anos), do sexo feminino, com exceção dos cursos de Medicina e Educação Física, em que a maioria foi do sexo masculino, provém de famílias convencionais, de origem cristã, em sua maioria de afiliação católica, herdada de família.

Pais dos ingressantes na UFTM têm, em sua maioria, nível de escolaridade médio e superior, e renda familiar entre três e seis salários mínimos (61\%). Entretanto, apenas 37,2\% dos alunos estudaram durante o período pré-universitário em escolas públicas, refletindo o pensamento de alguns autores sobre a desigualdade social brasileira. Jovens que cursam o ensino fundamental e médio em escolas públicas, de qualidade inferior à do ensino privado, têm menores chances de cursar o ensino superior nas universidades públicas, consideradas melhores do que as privadas, perpetuando-se a desigualdade social $^{8,9}$.

Segundo resultados apresentados pelo IBGE referentes ao último censo populacional de 2010, a população brasileira é de maioria cristã, de afiliação católica, mas, em comparação com o censo de 2000, há uma redução do número de católicos e crescimento do número de evangélicos em todas as regiões do Brasil. Também houve um crescimento da religião espírita $(1,3 \%-2 \%)$ e do número de pessoas que não são afiliadas a nenhuma religião $(7,4 \%-9 \%)^{10}$.

A distribuição de afiliação religiosa dos ingressantes analisados (Tabela 2) demonstra serem de maioria católica $(43,2 \%)$, e em seguida vem a religião espírita $(13,7 \%)$, que predomina sobre a evangélica (10,3\%). Além disso, seis alunos se autodefiniram como católicos e espíritas simultaneamente, e um católico se autodefiniu como católico praticante de candomblé. Estes dados refletem o sincretismo religioso da população brasileira; o percentual maior de espíritas reflete a força desta afiliação na Região Sudeste e, sobretudo, no Triângulo Mineiro, de acordo com os dados do IBGE ${ }^{10}$.

Ainda que a maioria dos ingressantes seja de católicos, seu percentual é menor do que o percentual obtido pelo IBGE (43,2\% x 64,6\%). Um percentual considerável, 27,9\% ( $n=51)$, referiu não ser afiliado a qualquer religião. No censo de 2010, esta característica apareceu em 9\% dos entrevistados. A distribuição da afiliação religiosa por cursos (Tabela 3) parece refletir o resultado geral, mas o que chama a atenção é que $56 \%$ dos ingressantes em Psicologia não têm afiliação religiosa.

A maioria dos ingressantes está completando a adolescência (mediana da idade: 19 anos) e herdou a afiliação religiosa dos pais. Entretanto, é nesta faixa etária que surgem os questionamentos religiosos e de valores sociais como um todo. Talvez os estudantes de Psicologia sejam os mais questionadores e tenham certa predisposição a buscar um caminho em direção à espiritualidade em detrimento do engajamento a uma religião organizada. Este aspecto da herança da religião familiar parece contribuir para a compreensão de que, ainda que a maioria dos indivíduos tenha afiliação religiosa, 56,8\% não vivenciam a religião em família ou na comunidade à qual dizem pertencer (Tabela 4), tendo, portanto, apenas a referência do rótulo legado pela tradição familiar.

Inúmeros autores conceituam espiritualidade como uma forma mais ampla de se relacionar com o transcendente do que o termo religiosidade ${ }^{11-14}$. Na percepção dos acadêmicos, $41,5 \%$ ( $n=76)$ concordam em que há diferença entre os dois termos, e, como era uma questão aberta, muitos deles emitiram seus próprios conceitos intuitivamente corretos. Entretanto, $26,7 \%(n=49)$ responderam que eram sinônimos, e 31,6\% ( $n=58)$ não se comprometeram em dar uma resposta; portanto, a maioria não soube diferenciar os dois conceitos, o que vem sendo encontrado por outros autores ${ }^{15}$.

As questões que abordam crenças espirituais relacionadas à religiosidade intrínseca demonstraram que a maioria dos acadêmicos considera a $\mathrm{R} / \mathrm{E}$ importante no que se refere a conferir sentido à vida e fortalecer nos momentos difíceis, e que gostaria de ter temas relacionados em seu currículo.

Esta expectativa de alunos ingressantes fornece um estímulo a que se continue a ministrar o curso "Saúde e Espiritualidade", oferecido a cada ano na UFTM como curso opcional na área da saúde ${ }^{16}$, a exemplo de outros cursos direcionados a estudantes de Medicina no Brasil ${ }^{17}$.

Atualmente, nos EUA e Reino Unido, conteúdos de Saúde e Espiritualidade já foram inseridos na maioria das escolas de Medicina ${ }^{18-19}$. No Brasil, poucas escolas o fizeram. Lucchetti et al. ${ }^{20}$ realizaram um levantamento em escolas de Medicina numa amostra de 86 escolas de um universo de 180 
existentes em 2012. Encontraram que apenas 10,4\% das escolas pesquisadas tinham cursos específicos de Saúde e Espiritualidade, embora a maioria dos coordenadores dos cursos (54\%) tenha respondido que considerava importante inserir a disciplina na grade curricular. Portanto, existe um longo caminho a percorrer.

Acreditamos que o ensino desta disciplina nas escolas, não só de Medicina mas em todas as áreas da saúde, poderá humanizar o próprio aluno, auxiliando-o a encontrar-se consigo mesmo no tocante à própria $\mathrm{R} / \mathrm{E}$ e também a tratar seu futuro paciente de forma integral.

Alguns alunos, sobretudo do curso de Serviço Social (55,6\%) responderam que sua $\mathrm{R} / \mathrm{E}$ interferiu na escolha profissional. Esta predisposição poderia ser potencializada pelo ensino de Saúde e Espiritualidade nesse curso.

Algumas respostas foram conflitantes: quando perguntados sobre o que pensavam acerca de possíveis benefícios e malefícios da R/E sobre a saúde, 94,5\% referiram que traz benefício e $47,6 \%$ acreditam que possa trazer malefícios, indicando que, para alguns, as duas opções estão corretas, o que condiz com o pensamento de alguns autores ${ }^{5,6,21}$. Entre os alunos espíritas, $100 \%$ responderam que creem na vida espiritual após a morte, enquanto a maioria dos alunos de outras religiões cristãs compartilha esta opção. Surpreendentemente, alunos que referiram não professar nenhuma religião compartilham este pensamento. Lucchetti et al. ${ }^{22}$, analisando as crenças de 3.630 acadêmicos de 12 escolas médicas brasileiras, encontraram resultados semelhantes: $66,8 \%$ referiram crer na existência de vida após a morte, 78,9\% referiram crer que o ser humano é constituído de corpo e alma, e 36,9\% ( $n=1.319)$ afirmaram crer na reencarnação, sendo que sua amostra se constituía de apenas $13 \%$ de espíritas $(n=370)$. Estas duas últimas perguntas não constavam do nosso questionário, mas estes dados, que também estão em acordo com o censo do IBGE de $2010^{10}$, demonstram que a população brasileira, mesmo de jovens, manifesta sua transcendente espiritualidade independentemente da religiosidade ou da herança religiosa familiar, corroborando o conceito de memória coletiva de Halbwachs ${ }^{23}$. Segundo esse autor, ações, atitudes e crenças não são processos atribuídos exclusivamente ao indivíduo ou a sua memória; ele utiliza palavras e ideias que tomou emprestado do seu ambiente ou de sua comunidade.

Parece ser intrínseca à maioria dos seres humanos a intuição de permanência ou de não dissolução após o momento da morte, e o profissional da saúde que souber trabalhar estas crenças, em si e nos seus pacientes, poderá potencializar e humanizar o seu cuidado ou assistência na área de sua escolha profissional $^{24}$.
Conclui-se que a maioria dos ingressantes na UFTM no período estudado, nas áreas selecionadas para análise, tem percepção da importância da R/E em suas vidas e traz expectativas de que o currículo do curso escolhido contemple a integralidade do cuidado em saúde, incluindo o tema em sua formação profissional.

\section{REFERÊNCIAS}

1. Lyons AS, Petrucelli II RJ. História da Medicina. São Paulo: Editora Manole Ltda, 1ª Edição Brasileira 1997.

2. Gussi MA, Dytz JLG. Religião e espiritualidade no ensino e assistência de enfermagem. Rev Bras Enferm. 2008; 61(3):377-384

3. Koenig HG, King DE, Carsin VB. A history of religion, medicine and healthcare. In: Handbook of Religion and Health. Oxford University Press, New York, $2^{\text {nd }}$ edition, 2012. p. $15-34$

4. Saad M, Masiera D, Baltistella LR. Espiritualidade baseada em evidências. Acta Fisiatrica. 2001; 8(3):107-112

5. Koenig HG. Religion, spirituality and medicine applications to clinical practice. MSJAMA - JAMA. 2000; 284(13):1708

6. Koenig HG. Religion, spirituality and health: the research and clinical implications. ISRN Psychiatry. 2012; 2012:1-33

7. Koenig HG, Büssing A. The Duke University Religion Index (DUREL): a five-item measure for use in epidemiological studies. 2010; 1(1):78-85.

8. Melsert ALM, Bock AMB. Dimensão subjetiva da desigualdade social: estudo de projetos de futuro de jovens ricos e pobres. Educ Pesqui São Paulo. 2015; 41(3):773-790

9. Corbucci PR, Cassiolato MM, Codes AL, Chaves JV. Situação educacional dos jovens brasileiros. In: Castro JÁ, Aquino LMC, Andrade CC(Org.) Juventude e Políticas Sociais no Brasil. Brasília, DF: IPEA, 2009, 91-108.

10. Brasil. Ministério do Planejamento, Orçamento e Gestão. Instituto Brasileiro de Geografia e Estatística- IBGE. Censo Demográfico 2010. Características gerais da população, religião e pessoas com deficiência. Rio de Janeiro, 2010; p.89105. [capturado em: 10 maio 2016] disponível em:http:/ / biblioteca.ibge.gov.br/visualizacao/periodicos /94/ cd_2010_religiao_deficiencia.pdf

11. Soeken KL, Carsin VJ. Responding to the spiritual need of the chronically ill. Nurs Clin North Am. 1987; 22(3):603-611

12. McKee DD, Chappel JN. Spirituality and medical practice. J Fam Pract, 1992; 35(2):201-208

13. Puchalski CM, Larson DB, Post SG. Physicians and patient spirituality. Ann Inter Med. 2000; 133(9):748-749 
14. Anandarajah G, Hight E. Spirituality and medical practice: using the HOPE questions as a practical tool for spiritual assessment. Am Fam Physitian. 2001; 63(1):81-89

15. Borges DC, Anjos GL, Oliveira LR, Leite JR, Lucchetti G. Saúde e espiritualidade e religiosidade na visão dos estudantes de medicina. Rev Bras Clin Med. São Paulo, 2013; 11(1):6-11

16. Borges MF, Freire M, Salles C, Palhares H, Fonseca E, Resende E. A disciplina "Saúde e Espiritualidade": uma experiência na Universidade Federal do Triângulo Mineiro. Rev Bras Educ Med. 2007; 31(2): Suplemento 161-162.

17. Dal-Farra RA, Geremia C. Educação em saúde e espiritualidade: proposições metodológica. Rev. Bras Edu Méd. 2010; 34(4):587-597

18. Koenig HG, Hooten EG, Lindsay-Calkins E, Meados KG. Spirituality in medical school curricula: findings from a national survey. Int J Psychiatry Med. 2010; 40:391-398

19. Neely A, Minford EJ. Current status of teaching on spirituality in UK medical schools. Med Educ, 2008; 42:176-182

20. Lucchetti G, Lucchetti ALG, Espinhosa DCM, Oliveira LR, Leite JR, Koenig HG. Spirituality and health in the curricula of medical schools in Brazil. BMC Med Educ [on line]. 2012; [capturado 11 maio 2016]; 12:78. Disponível em: http:/ / www.biomedcentral.com/1472-6920/12/78

21. Dalgalarrondo P, Marín-Léon L, Botega NJ, Berti De Azevedo Barros M, Bosco De Oliveira H. Religious affiliation and psychiatric morbidity in Brazil: higher rates among evangelics na spiritists. Int J Soc Psychiatry. 2008; 54(6):562-574

22. Lucchetti G, Oliveira LR, Koenig HG, Leite JR, Lucchetti ALG, and for the SBRAME Collaborators. Medical students, spirituality and religiosity - results from the mul- ticenter study SBRAME. BMC Med Educ [on line]. 2013; [capturado 11 maio 2016]; 13:162. Disponível em: http:/ / www.biomedcentral.com/1472-6920/13/162

23. Halbwachs M. A memória coletiva. São Paulo (SP): Centauro: 2006.

24. Santos FS, Incontri D. A arte de cuidar: saúde, espiritualidade e educação. O Mundo da Saúde, São Paulo. 2010; 34(4):488-497.

\section{CONTRIBUIÇÃO DOS AUTORES}

Tassiani Turra Ferreira: escreveu o projeto, selecionou os alunos, conduziu as entrevistas e redigiu o trabalho.

Maria de Fátima Borges: idealizou, coordenou e orientou o projeto, o trabalho e auxiliou a autora em sua redação.

Guilherme Cia Zanetti, Gustavo Luiz Lemos, Eduardo Souza Gotti: auxiliaram na redação do projeto e nas entrevistas. Janaíne Machado Tomé e Adriana Paula da Silva: auxiliaram no trabalho estatístico e executaram a parte gráfica do artigo. Elisabete Aparecida Mantovani Rodrigues de Resende: orientou os alunos na redação do projeto e na seleção dos entrevistados.

\section{CONFLITO DE INTERESSES}

Nada a declarar.

\section{ENDEREÇO PARA CORRESPONDÊNCIA}

Maria de Fátima Borges, Praça Dr Thomaz Ulhôa, 50 CEP: 38025-050 Bairro: Abadia, Uberaba-MG, Brazil. Email:borgmf@ uol.com.br, Phone: 34 99940806, Fax: 3433338710

Qui-quadrado com análise de resíduos

ERRATA EM: REVISTA BRASILEIRA DE EDUCAÇÃO MÉDICA, VOLUME 42, NÚMERO 1, JANEIRO-MARÇO 2018. ERRATUM IN: BRAZILIAN JOURNAL OF MEDICAL EDUCATION, VOLUME 42, ISSUE 1, JANUARY-MARCH 2018.

DOI: http:/ /dx.doi.org/10.1590/1981-52712018v42n1RB20160044 ( Percepção de Acadêmicos de Medicina e de Outras Áreas da Saúde e Humanas (Ligadas à Saúde) sobre as Relações entre Espiritualidade, Religiosidade e Saúde). Revista Brasileira de Educação Médica. 2018; 42(1):65-72.

Omissão dos autores:

Tassiani Turra Ferreira ${ }^{\mathrm{I}}$

Maria de Fátima Borges

Universidade Federal do Triângulo Mineiro, Uberaba, Minas Gerais, Brasil. 